\title{
Faster switching of energy suppliers - a blockchain-based approach
}

\author{
Michael Hinterstocker ${ }^{1 *}$, Florian Haberkorn ${ }^{1,2}$, Andreas Zeiselmair ${ }^{3}$ and Serafin von Roon ${ }^{1}$ \\ From The 7th DACH+ Conference on Energy Informatics \\ Oldenburg, Germany. 11-12 October 2018
}

\author{
* Correspondence: \\ mhinterstocker@ffe.de \\ ${ }^{1}$ Forschungsgesellschaft für \\ Energiewirtschaft mbH, Munich, \\ Germany \\ Full list of author information is \\ available at the end of the article
}

\begin{abstract}
Only a small share of German households make use of the opportunity to regularly switch their electricity supplier in order to fulfill their needs. Besides the relatively low possible monetary savings, another reason is the fact of long running contracts. The process of supplier switching for stakeholders in the energy market is quite timeconsuming. This is caused by inefficient design of the process steps due to a lack of automation, of common data management and of direct communication between these stakeholders.

Two options for optimizing this by means of a blockchain-based system are described and discussed here. These allow simplified communication between participating parties and therefore potentially quicker completion of the process. They enable automation of the whole process, prevent delays due to inconsistent data and therefore, allow intraday switching. An exemplary proof-of-concept implementation on the Ethereum blockchain shows the feasibility of the approach. Nevertheless, the advantages and disadvantages when compared to an alternative automated implementation, which is not blockchain-based, are still to be thoroughly examined.
\end{abstract}

Keywords: Supplier switching, Blockchain, Market communication, Roaming

\section{Introduction}

Currently, the supplier switching process of retail customers in the German energy market takes several days up to 3 weeks, since it involves numerous steps of data exchange, validation and confirmation between all affected market roles. Therefore, switching intervals lower than a month cannot be reasonably realized in the current system, leading to contract durations of at least 1 month, usually 1 year. This reduces the flexibility of retail customers to adapt to the market setting, since it is not possible to make use of potentially more economic offers. Moreover, this can also pose market entry barriers for new player, since only a very limited share of customers are able to switch in a given interval of time, increasing the required time for new players to accumulate a competitive customer base. Therefore, the current system potentially prevents increased competition in the electricity retail market.

These observations show that an automatized solution for the described processes might offer considerably shorter switching times, enabling the retail customer to choose the optimal supplier on a daily or sub-daily base. This is also in accordance

(c) The Author(s). 2018 Open Access This article is distributed under the terms of the Creative Commons Attribution 4.0 International License (http://creativecommons.org/licenses/by/4.0/), which permits unrestricted use, distribution, and reproduction in any medium, provided you give appropriate credit to the original author(s) and the source, provide a link to the Creative Commons license, and indicate if changes were made. 
with the EU's so-called winter package, which demands "improving the customer experience around day-to-day operations such as billing and switching" (European Commission, 2016). Therefore, the main goal here is to improve both the communication between market actors and the internal processes for validation and confirmation. This can be achieved by appropriate IT infrastructure, which serves as a communication backbone for the whole process and ensures data consistency. The process involves several parties with potentially conflicting interests, such as grid operators, metering point operators, consumers and suppliers.

Therefore, blockchain technology is identified as a possible solution for this application (Bogensperger et al., 2018). Potential benefits are distributed data, the immanent validation mechanism and the low barriers for participation in the system. A proof of concept shows the general approach and allows evaluating these benefits, as well as a comparison to alternative implementations such as traditional databases.

\section{Current situation}

The process for switching of energy suppliers in Germany is defined in a framework document called GPKE ("Geschäftsprozesse für die Kundenbelieferung mit Energie") (Bundesnetzagentur, 2006). These consist of 8 steps, which specify conclusion of contract, data transmission, validation and confirmation between the involved parties: current supplier, new supplier, distribution system operator, metering point operator and retail consumer. Data is mainly routed through the distribution system operator, which potentially causes inefficient processing. Moreover, several steps require manually checking the consistency and validity of transmitted data (e. g. customer details), which also affects the duration of the whole process negatively.

Due to liberalization of the energy market, about 1400 suppliers offer electrical energy to retail customers in Germany. These are connected to almost 900 different distribution system operators. Although there are standardized formats and procedures for market communication, the variety of these market participants leads to additional problems in the communication, since the individual level of implementation of these standards differs vastly. Therefore, additional manual interaction is required in order to correct erroneous data.

\section{Concepts for blockchain-based implementation}

A blockchain as a special type of distributed database offers some key features to the user. These include immutability, transparency, independence from central authorities and decentralized data storage (Bogensperger et al., 2018). In the use case discussed here, this has several advantages for all participating parties: the validity of customer details and of the assignment of customers to suppliers can be checked and ensured at any given time, the distribution system operator as intermediate party for data exchange can be skipped in order to achieve more efficient communication, and also the communication between retail customer and supplier can be included in the system.

Automation is sometimes also quoted as a distinctive feature of blockchain platforms, but alternative implementations based on conventional IT architecture can provide this as well. Nevertheless, the potential benefits of a blockchain-based system justify closer 
examination in order to analyze different options of implementation, its performance and its applicability in the energy market.

Two different concepts for this system are presented. The first one, illustrated in Fig. 1, is based on tokens on the blockchain, which represent the right to supply a certain customer with electrical energy. For this, the concept of non-fungible tokens, which is available on the Ethereum platform, is applied (Entriken, 2018). These tokens are uniquely created and carry additional metadata, in this case e. g. metering point id, distribution system operator, end of contract and notice period. A smart contract enables the customer to retrieve and destroy the token in order to switch suppliers. This can be extended to only allow switching after payment has been registered. In this case, an oracle is applied to integrate the metered consumption in order to determine the amount payable. Alternatively, the payment can be processed on-chain via a different class of tokens, similar to cryptocurrencies. All involved grid operators continuously validate the data as new blocks are written, ensuring consistent data for all participants. Therefore, the appropriate consensus algorithm for this application is proof of authority, which avoids the common disadvantages of proof-of-work-based blockchain systems, such as high computational effort and high energy consumption.

This approach has the advantage of being intuitive given that the currently most widespread applications of blockchain are cryptocurrencies, which mainly require tokens to be transferred. Nevertheless, it is quite complex to implement and rather inflexible for further extensions regarding related use cases.

The second concept, schematically depicted in Fig. 2, utilizes the mapping feature of the Ethereum blockchain platform. This allows assigning additional data to public addresses of the blockchain system, thus avoiding the complex process of creating, transmitting and destroying tokens for every switching process. As for the previously described concept, these data include information about the consumer such as metering point id, contract details and distribution system operator details. Additionally, the current supplier is stored here, since this assignment is not represented by token ownership.

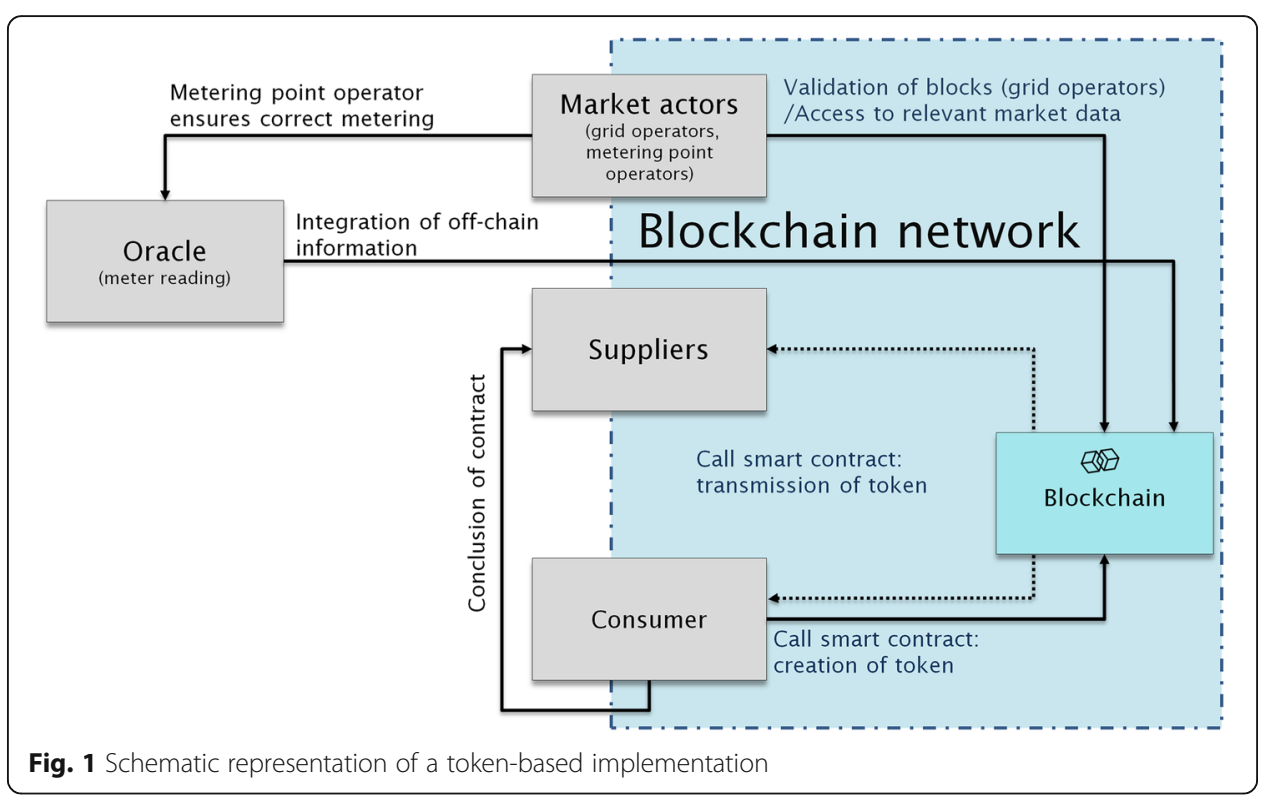




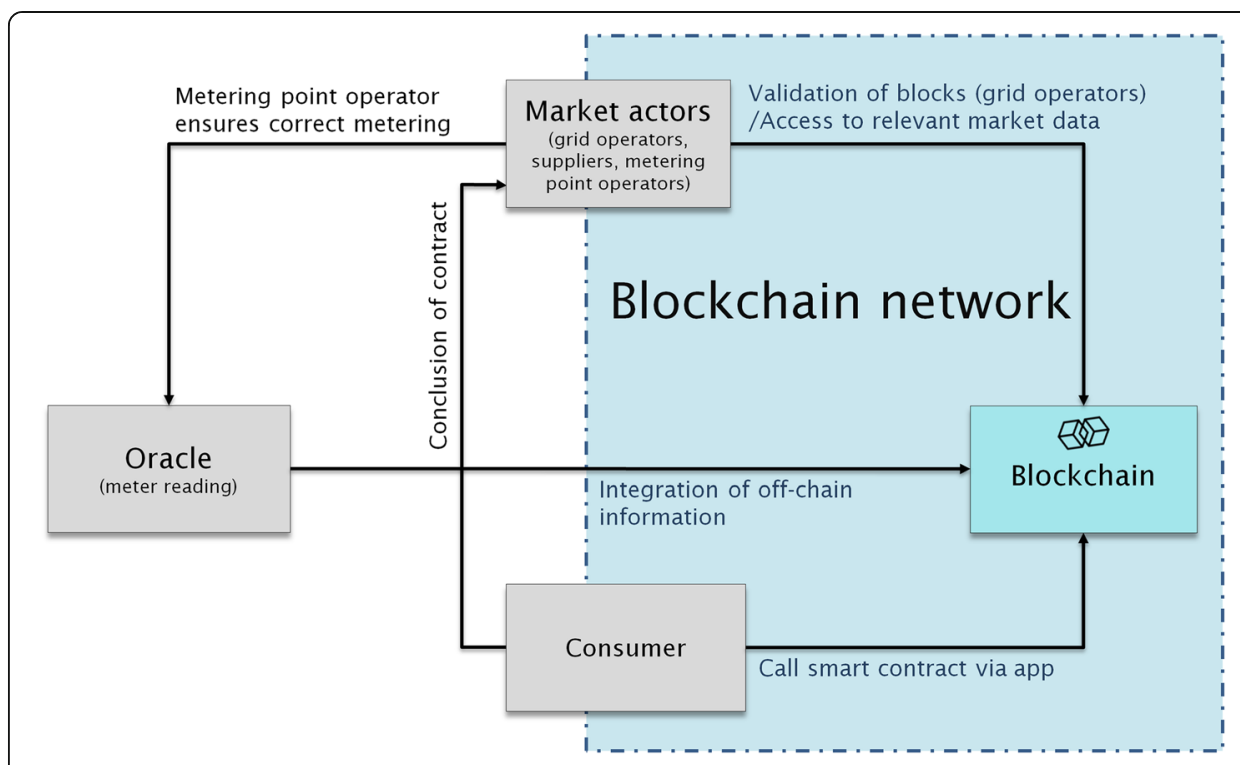

Fig. 2 Schematic representation of a mapping-based implementation

The actual switching process is based on a smart contract, which is called by the customer and assigns new data to his address. Within the smart contract, accordance to contractual conditions and consistency of the data is ensured. Due to the immanent validation by involved grid operators, the resulting data is guaranteed to be correct. This concept can also be implemented as a proof-of-authority blockchain. All relevant market actors can access and read the full state of the system at any given time; therefore, the assignment of consumers to suppliers is sufficiently represented by this approach.

This concept can also be extended to include payment via an analogous approach as described before. In this case, the smart contract which is invoked for switching also checks the correctly processed payment.

The implementation of a proof of concept on the Ethereum platform shows that this approach can be realized with comparably low effort. The test environment allows examining proper functionality, as well as sufficiently low processing time below the currently applied metering interval of $15 \mathrm{~min}$.

\section{Extensions}

A comprehensive implementation and application of the switching process as described in the second (mapping-based) approach has the additional advantage of being easily extendable in order to include additional features and therefore, to utilize the established communication infrastructure for further use cases. The possibility to change the assigned supplier at a given location allows introducing a roaming functionality, enabling consumers to also use their preferred supplier when away from home by switching the supplier of their current location and returning to the default value afterwards. This can prove useful for applications such as charging an electric vehicle at public charging stations or for settlement of electricity consumption at holiday homes. 
The infrastructure can also be extended to support the switching process of metering point operators. Although this is not very common in the German market now, the implementation of a new market communication system poses the opportunity to include this and therefore, to also make this process more efficient and accessible.

This more efficient way of market communication also enables potential new business models, such as special customer services regarding automated switching, energy mix preferences or the geographical origin of produced energy.

\section{Conclusions}

The analyses demonstrate potential for improvement in the current processes of switching suppliers in Germany. Two concepts show that a blockchain-based approach is a possible solution to this, but also evinces some drawbacks when compared to conventional databases. The main temporal advantage is expected to be caused simply by automation of the whole process, which does not necessarily require a blockchain to be achieved. Moreover, alternative approaches might be cheaper in terms of hardware, computational power and storage requirements.

Nevertheless, an exemplary implementation of a proof of concept on the Ethereum platform shows that the general concept is feasible. In order to reliably assess and compare the approach to a centralized one, the implementation of both options and the application to real-world demands is necessary.

Implementation of the described system and the corresponding regulatory adjustments are expected to reduce market entry barriers for suppliers, leading to increased competition in the market. Also the possibility to switch suppliers in intervals down to $15 \mathrm{~min}$ and even less increases price pressure on the supply side. This in turn can cause a countermovement on the long run, since smaller suppliers might not be able to cope with reduced profit margins, decreasing the overall number of suppliers in the market again.

\section{Abbreviations}

EU: European Union; GPKE: Geschäftsprozesse für die Kundenbelieferung mit Energie; IT: Information Technology

\section{Acknowledgements}

We would like to thank our partners Innogy, SMA, Stadtwerke Augsburg, Thüga, TransnetBW, VBEW, Verbund and IIIwerke VKW for supporting this project.

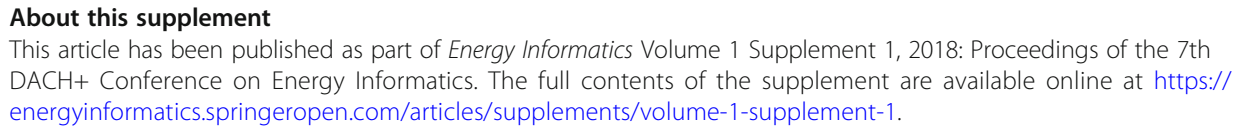

\section{Authors' contributions}

$\mathrm{MH}$ devised the project, defined the scope and developed the main conceptual idea in discussion with AZ. FH worked out the technical details, implemented the proof of concept and evaluated the concepts, supported and reviewed by $\mathrm{MH}$ and AZ. SvR supervised the project. $\mathrm{MH}$ wrote the paper with contributions by FH. All authors discussed the results and commented on the paper. All of the authors have read and approved the final manuscript.

Competing interests

We have no competing interests to declare.

Publication costs for this article were sponsored by the Smart Energy Showcases - Digital Agenda for the Energy

Transition (SINTEG) programme.

\section{Publisher's Note}

Springer Nature remains neutral with regard to jurisdictional claims in published maps and institutional affiliations. 
Author details

${ }^{1}$ Forschungsgesellschaft für Energiewirtschaft mbH, Munich, Germany. ${ }^{2}$ Ulm University, Ulm, Germany.

${ }^{3}$ Forschungsstelle für Energiewirtschaft e.V, Munich, Germany.

Published: 10 October 2018

\section{References}

Bundesnetzagentur (2006) Geschäftsprozesse zur Kundenbelieferung mit Elektrizität. Bonn

European Commission (2016) Clean Energy for All Europeans. Brussels

Entriken W (2018) ERC-721 Non-Fungible Token Standard. Ethereum Foundation

Bogensperger A, Zeiselmair A, Hinterstocker M (2018) Die Blockchain-Technologie - Chance zur Transformation der Energieversorgung? Forschungsstelle für Energiewirtschaft e.V, Munich

Submit your manuscript to a SpringerOpen ${ }^{\circ}$ journal and benefit from:

- Convenient online submission

- Rigorous peer review

- Open access: articles freely available online

- High visibility within the field

- Retaining the copyright to your article

Submit your next manuscript at $\boldsymbol{\nabla}$ springeropen.com 